\title{
Diagnosis of tubercular uveitis by quantitative polymerase chain reaction
}

\author{
Pooja Sharma $\cdot$ Reema Bansal • Vishali Gupta • \\ Amod Gupta
}

Received: 8 July 2010 / Accepted: 23 August 2010 /Published online: 11 November 2010

(C) The Author(s) 2010. This article is published with open access at Springerlink.com

\begin{abstract}
Purpose To report the use of real-time or quantitative polymerase chain reaction (qPCR) in confirming the diagnosis of tubercular uveitis.

Methods A qPCR assay using primers targeting the MPB64 gene of Mycobacterium tuberculosis (MTB) was developed. A standard curve for quantification of mycobacterial load was generated. Vitreous fluid samples from patients presumed to have tubercular uveitis were assayed to identify and quantify the mycobacterial load. The amount of the test sample product was interpolated from the standard curve of cycle threshold values generated from known starting copy number of standard MTB DNA.

Results The copies of MTB genomes in the three test samples studied were found to be $7.61 \times 10^{4}, 4.53 \times 10^{4}$, and $1.43 \times 10^{5}$, respectively.

Conclusion qPCR detected and quantified MTB genome from the vitreous fluid of eyes clinically suspected with tubercular uveitis.
\end{abstract}

Keywords Quantitative polymerase chain reaction.

Tuberculosis · Tubercular uveitis

Polymerase chain reaction (PCR) is a molecular technique for evaluation of very small amounts of DNA and RNA by enzymatic amplification of nucleic acid sequences [1]. Several studies have linked specific pathogens to ocular

P. Sharma $\cdot$ R. Bansal $\cdot$ V. Gupta $\cdot$ A. Gupta $(\bowtie)$

Department of Ophthalmology, Advanced Eye Centre,

Post Graduate Institute of Medical Education and Research,

Chandigarh 160012, India

e-mail: eyepgi@sify.com inflammatory syndromes using PCR [1]. It has had a major impact on our ability to detect infectious agents causing uveitis, including viral uveitis, mycobacterial intraocular infections, infectious endophthalmitis, and protozoa eye diseases [2]. The first use of PCR in detecting Mycobacterium tuberculosis (MTB) from the eye was reported from aqueous samples of two patients with active retinal vasculitis [3].

Quantitative (qPCR) or real-time PCR is a variant of PCR using fluorescent probes [4] or SYBR Green dye [5] which better allows the quantification of nucleic acid in the sample. It facilitates the monitoring of the progress of a PCR reaction in real time. One can start with minimal amounts of nucleic acid and quantify the end product accurately. There is no need for the post-PCR processing which saves the resources and the time.

qPCR has been applied to infectious posterior uveitis caused by viral infections and Toxoplasma gondii [6]. In a clinicopathological study, it revealed the presence and quantified the number of copies of MTB in the retinal pigment epithelium (RPE) of an eye with granulomatous panuveitis [5].

We report the use of qPCR in confirming tubercular uveitis in three clinically suspected patients.

\section{Methods}

In a retrospective study, saved DNA from the vitreous samples of three patients clinically suspected and found positive for MTB by conventional PCR was used for qPCR to confirm and quantitate the bacterial load. We used the same set of primer pairs as used in the conventional PCR. This allowed us to confirm our positive results through the use of two PCR combinations. 
The DNA was extracted from the vitreous fluid sample using DNeasy tissue kit (QIAGEN, Hilden, Germany) according to the manufacturer's instructions. The extracted DNA specimens were stored at $-20^{\circ} \mathrm{C}$ until used. We used MPB64 gene primers for the detection of MTB genome that was a part of previously validated multiplex PCR assay for the diagnosis of posterior uveitis [7].

The qPCR was performed using the forward primer MPB1 (5'-TCC GCT GCC AGT CGT CTT CC-3') and reverse primer MPB2 (5'-GTC CTC GCG AGT CTA GGC CA-3'), which amplified a 240-base-pair fragment of the MPB64 single copy gene. The experiments were run in triplicate with Light cycler 480 real-time PCR system (Roche Applied sciences) and SYBR ${ }^{\circledR}$ Premix Ex Taq ${ }^{\mathrm{TM}}$ (Maxima TM SYBR Green qPCR Mastermix, Fermentas Life Sciences) under reaction conditions which consisted of a single step of 10 -min incubation step at $95^{\circ} \mathrm{C}$, followed by four cycles of $95^{\circ} \mathrm{C}, 60^{\circ} \mathrm{C}$, and $72^{\circ} \mathrm{C}$ for $30 \mathrm{~s}$ each, and 34 cycles consisting of $95^{\circ} \mathrm{C}, 56^{\circ} \mathrm{C}$, and $72^{\circ} \mathrm{C}$ for $30 \mathrm{~s}$ each. To confirm the specific target amplification, the real-time amplification was followed by melting curve analysis from $65^{\circ} \mathrm{C}$ to $95^{\circ} \mathrm{C}$. Non-template controls (NTC, consisting of nuclease-free $\mathrm{H}_{2} \mathrm{O}$ ) were used as negative controls for amplification. The primer concentrations in the reaction mixtures of $25 \mu \mathrm{l}$ were $600 \mathrm{nM}$ for each forward and reverse primer. A total of $8 \mu \mathrm{l}$ of DNA extracted from the vitreous fluid sample was used as a PCR template. A total of five standards prepared by cloning PCR amplified product corresponding to MPB64 gene of MTB H37Rv strain in pGEM-T easy vector. The plasmids DNA for the copy number corresponding to a concentration from $10^{3}$ to $10^{7}$ copies of MTB bacterial genomes were used in the present study.

\section{Results}

Amplification signals were observed for all the three test samples studied (Fig. 1a, b). The melting curve analysis indicated that the corresponding PCR products were specific as a single peak was observed in both the MTB standards and the test samples having a melting temperature (Tm) of $88-90^{\circ} \mathrm{C}$ (Fig. 1c). The MTB standard DNA and the three test samples were subjected to test in triplicates and the mean value for copy numbers was calculated. The standard curve was constructed based on crossing point (Cp) values that demonstrated a significant linear relationship $\left(R^{2}=0.9959\right)$ between the $\mathrm{Cp}$ values and the log of the starting copy numbers for each of the standard MTB DNA (Fig. 2). The present study detected $7.61 \times 10^{4}, 4.53 \times 10^{4}$, and $1.43 \times 10^{5}$ copies of bacterial genome in the three test samples, respectively.
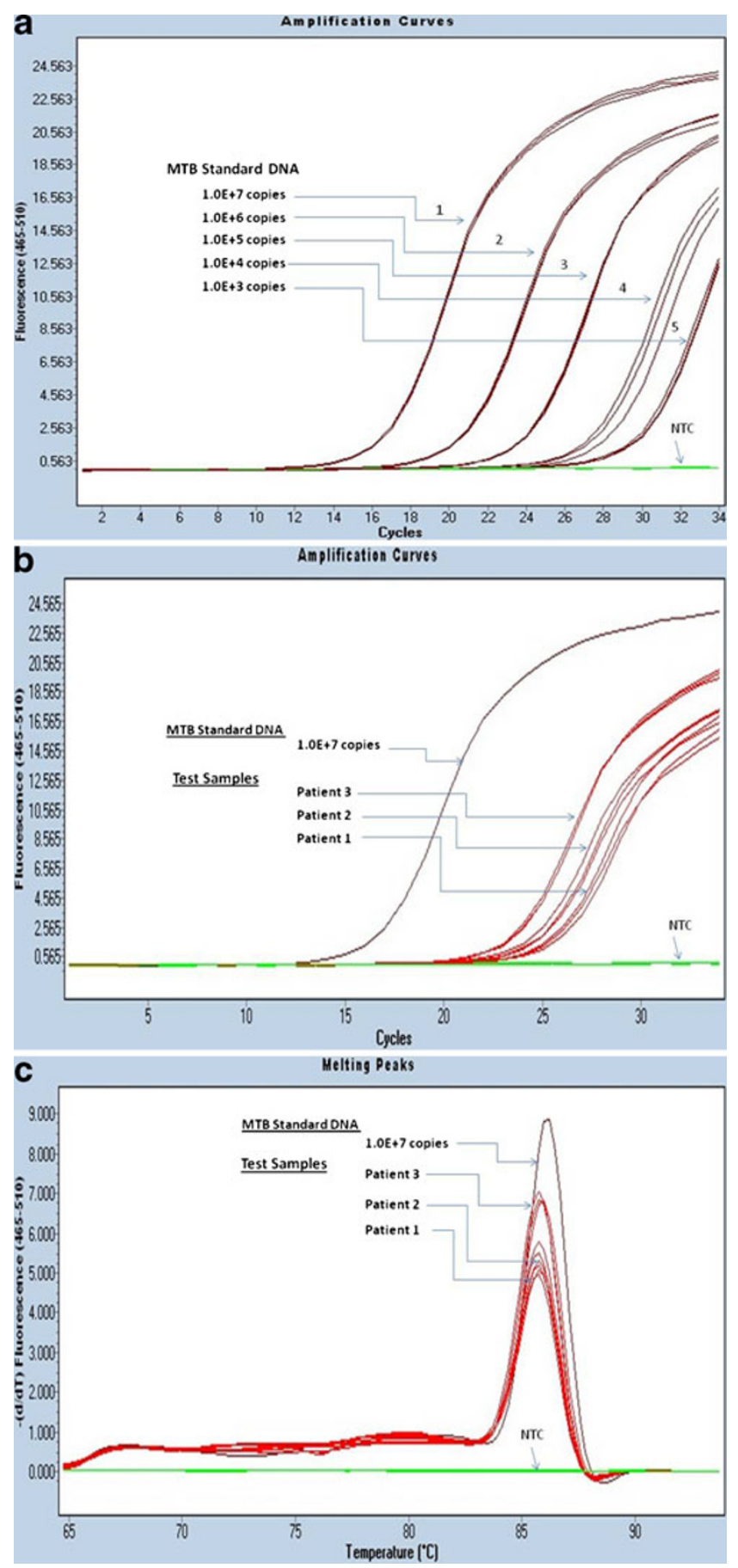

Fig. 1 a Amplification curve obtained from the analysis of Mycobacterium tuberculosis standard DNA run in triplicates ranging from $10^{7}$ to $10^{3}$ copies of bacterial genomes; $\mathbf{b}$ amplification curve obtained from the analysis of three test samples in triplicates including one MTB standard DNA as positive control; c melting curve analysis of the three test samples including one MTB standard DNA as positive control indicating the specificity of the reaction product. NTC non-template control

Case examples

Case 1 A 25-year-old male presented with sudden diminution of vision in the right eye since 4-5 months. 
Fig. 2 Mycobacterium tuberculosis DNA copies within the test samples by interpolating in the standard curve generated by the analysis of standard MTB DNA with known copy number $\left(10^{3}\right.$ to $\left.10^{7}\right)$

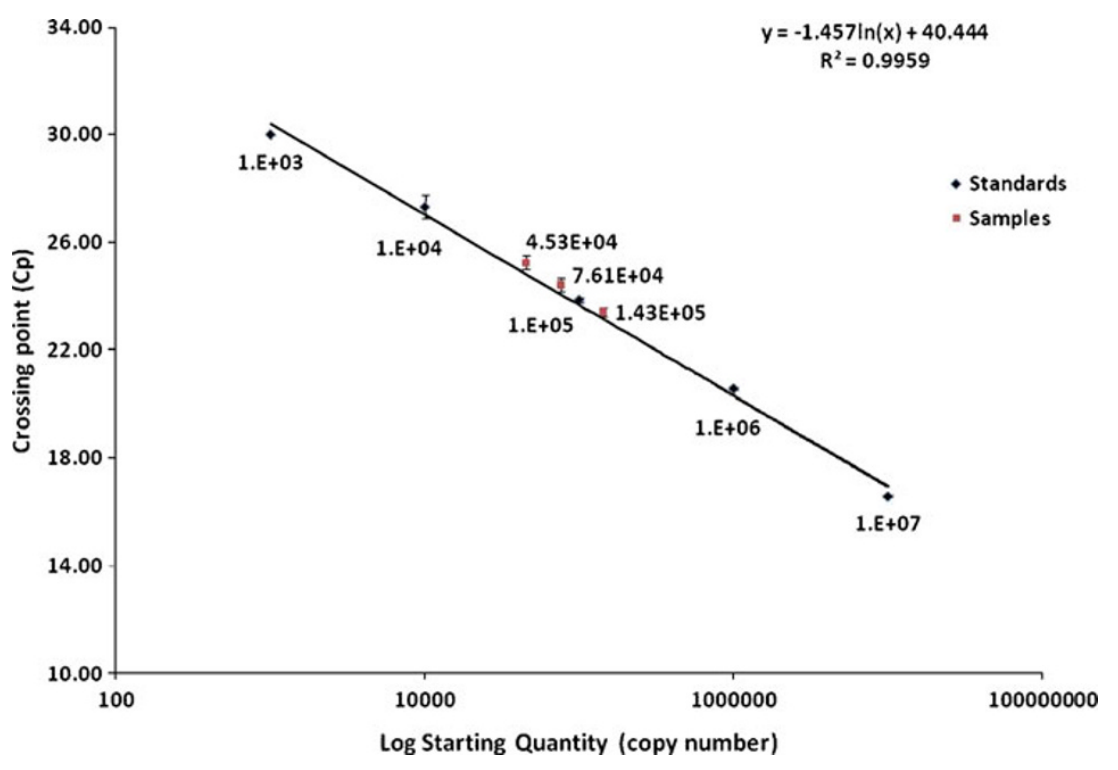

His best-corrected visual acuity (BCVA) was hand motion in the right eye and $6 / 6$ in the left eye. The intraocular pressures were 14 and $16 \mathrm{mmHg}$ in the right and left eye, respectively. The left eye examination was unremarkable. With a normal anterior segment, the right eye revealed dense gray vitreous hemorrhage on posterior segment examination and on B-scan ultrasound. The tuberculin skin test (TST) showed an induration of $19 \times$ $22 \mathrm{~mm}$. He underwent pars plana vitrectomy (PPV) and endolaser photocoagulation in the inferotemporal quadrant. Peroperatively, sheathing of inferotemporal vessels with retinal vascularization was noted. The vitreous fluid was sent for PCR analysis. He received oral prednisolone (1 $\mathrm{mg} / \mathrm{kg}$ daily) postoperatively. A MTB load of $7.61 \times 10^{4}$ was detected by qPCR in the vitreous sample. He was administered 4-drug antitubercular therapy. His BCVA is $6 / 6$ in the right eye at 4 months followup. The eye was quiescent and the fundus examination showed clear media, sheathed vessels inferotemporally, laser scars and regression of retinal neovascularization.

Case 2 A 35-year-old male with decreased vision in the left eye since 9 months had BCVA of 6/9 in the right eye and $6 / 60$ in the left eye. The intraocular pressures were 12 and $10 \mathrm{mmHg}$ in the right and left eye, respectively. He had posterior subcapsular cataract in both the eyes. Posterior segment examination was unremarkable in the right eye. Left eye had vitreous cells with snowballs. A subretinal mass lesion was present in the upper temporal quadrant with inferior peripheral exudative retinal detachment. (Figure 3a) The TST showed an induration of $16 \times 16 \mathrm{~mm}$. Vitreous tap of the left eye revealed a positive monoplex PCR, and mycobacterial load of $4.53 \times 10^{4}$ by qPCR. The patient received 4-drug antitubercular therapy and oral cortico- steroids ( $1 \mathrm{mg} / \mathrm{kg}$ daily). At 6 months, his BCVA is $6 / 12$ in the left eye with posterior polar cataract and a scar at the site of subretinal mass (Fig. 3b).

Case 3 A 40-year-old male with decreased vision in the left eye since 3 months had BCVA of $6 / 6$ in the right
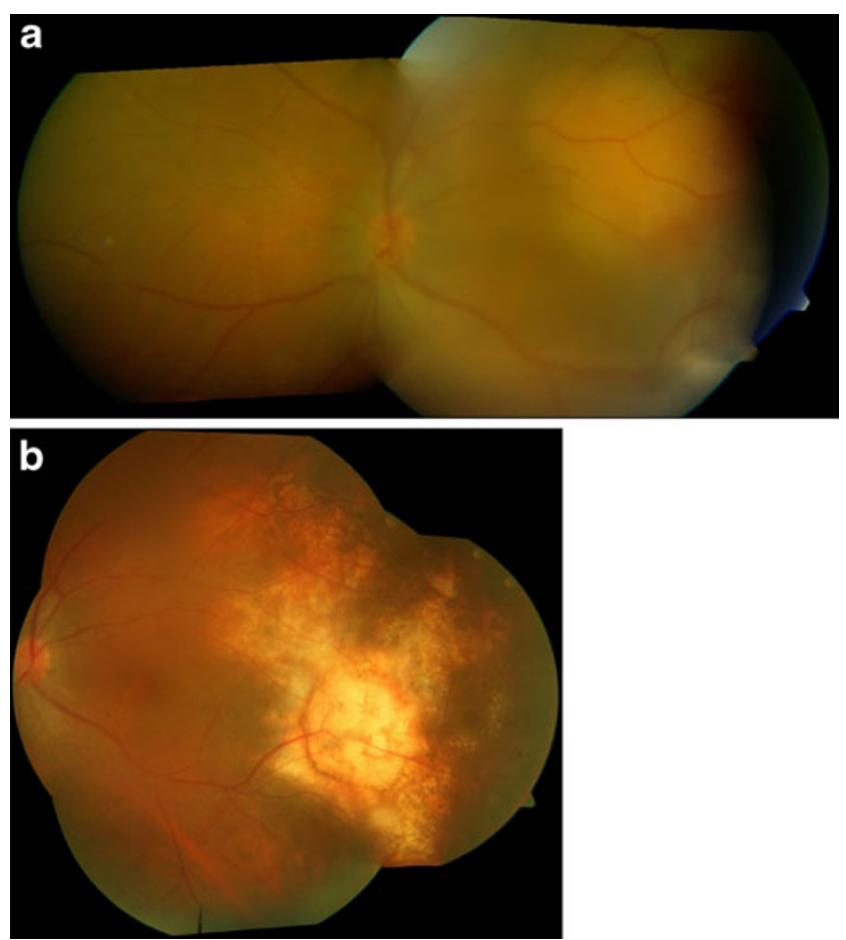

Fig. 3 Left eye fundus of case 2 showing subretinal mass in the upper temporal quadrant with exudative retinal detachment (a) and bestcorrected visual acuity (BCVA) of 6/60. Six months after treatment with antitubercular therapy and corticosteroids, the eye is quiescent with BCVA of 6/12 and a large temporal scar at the site of subretinal mass (b) 
and counting fingers in the left eye. The intraocular pressures were 16 and $12 \mathrm{mmHg}$ in the right and left eye, respectively. There was a relative afferent pupillary defect in the left eye. The right eye examination was unremarkable. The left eye fundus examination revealed extensive fibrovascular proliferation over the disc causing tractional retinal detachment. Retinal periphery showed sheathed vessels with healed choroiditis scars. The TST showed an induration of $40 \times 45 \mathrm{~mm}$. The patient underwent PPV for dissection of the fibrovascular membranes with endolaser photocoagulation and C3F8 tamponade. Monoplex PCR analysis of the vitreous fluid demonstrated MTB, and qPCR detected $1.43 \times 10^{5}$ bacterial genomes. Along with oral prednisolone (1 mg/kg daily), four-drug antitubercular therapy was added. At 4 months, the BCVA in the left eye was counting fingers limited by a large macular scar.

\section{Discussion}

Besides early and fast diagnosis of MTB, the main purpose of this study was to quantify the mycobacterial load using qPCR amplification technique in these patients. The results obtained by qPCR correlated with clinical diagnosis of tubercular uveitis in our patients. The finding of high mycobacterial loads in the ocular fluids indicates that mycobacterial replication takes place in the eye, suggesting a direct pathogenic role in intraocular inflammation. Though the inflammation in these eyes is clinically evident in retina and uvea, the evidence of their isolation from the RPE suggests their preferential localization in these cells [5]. Further, their isolation directly from the RPE may yield a higher bacterial load as compared to when they are extracted from the ocular fluids of eyes with posterior uveitis as seen in our patients.

Tubercular uveitis poses a major diagnostic challenge in endemic countries. In our experience, retinal vasculitis with or without choroiditis in patients with latent/manifest tuberculosis is a strong clinical predictor of tubercular uveitis [8]. The clinical markers of tubercular uveitis are considered in routine practice to initiate early eye-saving treatment. Inflammation of retinal vessels is a known association of systemic tuberculosis. The most common etiologies of retinal vasculitis in our experience are idiopathic and tuberculosis. We have previously described the clinical presentation of PCR-positive tubercular retinal vasculitis [9].

Specific diagnosis of the cause of infectious uveitis may be difficult in part because of limited availability of adequate ocular samples for diagnostic evaluation. Although culture is regarded as the gold standard for the diagnosis of tuberculosis [10], it is seldom available from the ocular specimens. A very low sensitivity of acid-fast bacilli smear and culture, particularly in ocular fluid specimens and long time period (6-8 weeks) for this bacteria to grow in culture are major limitations in diagnosing ocular tuberculosis in routine clinical practice.

The PCR has emerged as a powerful tool for rapid detection of the mycobacterial genome, with a high specificity and a variable sensitivity [3, 9, 11-13]. Aqueous humor, vitreous, or subretinal fluid and even tissue specimens have been used for PCR testing of MTB DNA, with promising results $[5,12,13]$. In eyes where the inflammation is predominantly confined to the posterior segment, vitreous specimen may be obtained for analysis by either straight needle vitreous aspiration or ideally PPV. Vitreous aspiration is easier to perform and can be done in an office setting, but carries an increased risk of retinal traction and detachment. Since most of the eyes with panuveitis or posterior uveitis have sight-threatening disease, these eyes may in addition benefit from PPV in terms of removal of the whole vitreous body and a higher diagnostic yield of the mycobacteria.

qPCR allows fast detection and quantification of pathogen load in the tested specimen, with a minimized risk of carryover and cross-contamination [14]. It may be helpful in confirming the diagnosis of clinically identified cases in laboratories having access to good research facilities. The prognostic or diagnostic significance of mycobacterial load in tubercular uveitis is as yet not known. However it is well known that tubercular uveitis may manifest clinically with variable clinical manifestation that may include chronic anterior uveitis, retinal vasculitis, and serpiginous-like choroiditis or even subretinal mass due to choroidal granuloma [8]. Recently, Rao et al. found $1.7 \times 10^{6}$ copies of MTB genome from the micro dissected RPE cells of paraffin embedded sections of the globe from a patient with panuveitis. The copy numbers $7.61 \times 10^{4}$ and $1.43 \times 10^{5}$ in our patients 1 and 3 , respectively, with the regressed disease (retinal vasculitis) were comparable to case 2 with active tubercular uveitis with subretinal mass lesion $\left(4.53 \times 10^{4}\right)$. The relatively lower number of copies of MTB in our cases compared to the previous report may be attributed to different sites of sampling (Vitreous fluid vs. RPE). Both these studies, however, justify a need to correlate the DNA load with clinical presentation in terms of morphology and severity of tubercular uveitis in a larger set of patients.

Conflicts of interest None of the authors have any proprietary interest. 
Open Access This article is distributed under the terms of the Creative Commons Attribution Noncommercial License which permits any noncommercial use, distribution, and reproduction in any medium, provided the original author(s) and source are credited.

\section{References}

1. Chi-Chao C, DeFen C, Tuo J (2005) Polymerase chain reaction in the diagnosis of uveitis. Int Ophthalmol Clin 45:41-55

2. Van Gelder RN (2001) Applications of the polymerase chain reaction to diagnosis of ophthalmic disease. Surv Ophthalmol 46:248-258

3. Kotake S, Kimura K, Yoshikawa K et al (1994) Polymerase chain reaction for detection of Mycobacterium tuberculosis in ocular tuberculosis [letter]. Am J Ophthalmol 117:805-806

4. Heid CA, Stevens J, Livak KJ, Williams PM (1996) Real time quantitative PCR. Genome Res 6:986-994

5. Rao NA, Saraswathy S, Smith RE (2006) Tuberculous uveitis: distribution of Mycobacterium tuberculosis in the retinal pigment epithelium. Arch Ophthalmol 124:1777-1779

6. Dworkin LL, Gibler TM, Van Gelder RN (2002) Real-time quantitative polymerase chain reaction diagnosis of infectious posterior uveitis. Arch Ophthalmol 120:1534-1539
7. Gupta V, Sachdeva N, Gupta A, Arora SK, Bambery P (2009) Multiplex PCR assay. Available at: http://patft.uspto.gov/netacgi/nphParser?Sect $1=$ PTO $1 \&$ Sect $2=$ HITOFF $\& d=$ PALL $\& \mathrm{p}=1 \& \mathrm{u}=\% 2$ Fneta $\mathrm{html} \% 2 \mathrm{FPTO} \% 2 \mathrm{Fsrchnum} . \mathrm{htm} \& \mathrm{r}=1 \& \mathrm{f}=\mathrm{G} \& \mathrm{l}=50 \& \mathrm{~s} 1=7,504,494$. PN.\&OS=PN/7,504,494\&RS=PN/7,504,494. Accessed 20 Aug 2010

8. Gupta A, Bansal R, Gupta V, Sharma A, Bambery P (2010) Ocular signs predictive of tubercular uveitis. Am J Ophthalmol 149:562-570

9. Gupta A, Gupta V, Arora S, Dogra MR, Bambery P (2001) PCRpositive tubercular retinal vasculitis: clinical characteristics and management. Retina 21:435-444

10. Dinnes J, Deeks J, Kunst H et al (2007) A systematic review of rapid diagnostic tests for the detection of tuberculosis infection. Health Technol Assess 11:1-196

11. Gupta V, Arora S, Gupta A, Ram J, Bambery P, Sehgal S (1998) Management of presumed intraocular tuberculosis: possible role of the polymerase chain reaction. Acta Ophthalmol Scand 76:679-682

12. Arora SK, Gupta V, Gupta A et al (1999) Diagnostic efficacy of polymerase chain reaction in granulomatous uveitis. Tuber Lung Dis 79:229-233

13. Gupta V, Gupta A, Rao NA (2007) Intraocular tuberculosis - an update. Surv Ophthalmol 52:561-587

14. Parashar D, Chauhan DS, Sharma VD et al (2006) Applications of real-time PCR technology to mycobacterial research. Indian J Med Res 124:385-398 